\title{
The influence of orthographic experience on the development of phonological preparation in spoken word production
}

\author{
Chuchu $\mathrm{Li}^{1} \cdot$ Min Wang ${ }^{2}$
}

Published online: 14 July 2017

(C) Psychonomic Society, Inc. 2017

\begin{abstract}
Three sets of experiments using the picture naming tasks with the form preparation paradigm investigated the influence of orthographic experience on the development of phonological preparation unit in spoken word production in native Mandarin-speaking children. Participants included kindergarten children who have not received formal literacy instruction, Grade 1 children who are comparatively more exposed to the alphabetic pinyin system and have very limited Chinese character knowledge, Grades 2 and 4 children who have better character knowledge and more exposure to characters, and skilled adult readers who have the most advanced character knowledge and most exposure to characters. Only Grade 1 children showed the form preparation effect in the same initial consonant condition (i.e., when a list of target words shared the initial consonant). Both Grade 4 children and adults showed the preparation effect when the initial syllable (but not tone) among target words was shared. Kindergartners and Grade 2 children only showed the preparation effect when the initial syllable including tonal information was shared. These developmental changes in phonological preparation could be interpreted as a joint function of the modification of phonological representation and attentional shift. Extensive pinyin experience encourages speakers to attend to and select onset phoneme in phonological preparation, whereas extensive character experience encourages speakers to prepare spoken words in syllables.
\end{abstract}

Chuchu Li

chl441@ucsd.edu

1 Department of Psychiatry, University of California, San Diego, 9500 Gilman Drive, La Jolla, CA 92093-0948, USA

2 University of Maryland, College Park, MD, USA
Keywords Orthographic experience $\cdot$ Phonological preparation $\cdot$ Spoken word production $\cdot$ Language development

Spoken word production involves the operation of a series of cognitive mechanisms. In a general architecture, spoken word production starts from message or concept encoding (e.g., identify an object in a picture), then moves to the retrieval of lexical items, retrieval and encoding of segments, syllabification, and finally articulation (Ferreira, 2010). However, a cross-linguistic difference may exist when speakers map a lexical item to its word form (i.e., phonological ingredients). The concept "proximate unit," which refers to the first selectable phonological unit at the initial stage of phonological encoding (i.e., the first phonological unit selected after lexical retrieval), was introduced to address this cross-linguistic difference (J.-Y. Chen, O'Séaghdha, \& Chen, 2016; T.-M. Chen \& Chen, 2013; O'Séaghdha, 2015; O'Seaghdha et al. 2010; Roelofs, 2015).

The literature on proximate unit has sometimes used other terminologies, reflecting different assumptions. For example, "functional unit" has also been used to explain the same concept (e.g., Ida, Nakayama, \& Lupker, 2015; Kureta, Fushimi, $\&$ Tatsumi, 2006). Although it emphasizes the functional role of the proximate unit, it does not exclude the functionality of units at other levels (i.e., the nonproximate units). On the other hand, some recent studies suggested that the proximate unit might be anticipated prior to the phonological encoding stage, which might be involved in preparation and involve central attention capacity, a mechanism that does not have to occur in the production pathway (e.g., O'Séaghdha \& Frazer, 2014). In the current study, we decided to use the term "preparation unit" as a broader and general term to refer to the starting point or the first selectable phonological unit at the initial stage of 
word form preparation in spoken word production. Consistent with the suggestion by O'Séaghdha and Frazer (2014), we argue that preparation may be distinguished from production, given that it may require attentional resources, and that preparation does not have to be stored in the production pathwayinstead, the entire word is encoded no matter whether and how the phonological information is prepared.

Previous research has investigated the preparation unit in adults from a number of perspectives, such as the influence of word properties (e.g., the influence of word length in Meyer, 1991), the flexibility of preparation unit within the same language (Kureta, Fushimi, Sakuma, \& Tatsumi, 2014; C. Li, Wang, \& Idsardi, 2015), the preparation unit across different languages (e.g., Kureta et al., 2006; O'Séaghdha et al., 2010), and the preparation unit in bilinguals (Ida et al., 2015; C. Li, Wang, \& Davis, 2015; Verdonschot, Nakayama, Zhang, Tamaoka, \& Schiller, 2013). However, limited research has been conducted to investigate the preparation unit in children and its developmental trajectory. The present study aimed to bridge this gap. Furthermore, the influence of children's orthographic experience was examined.

\section{The phonological preparation unit in adults}

The form preparation paradigm has been frequently used to investigate the preparation unit in spoken word production. In early studies, the form preparation paradigm was mostly adopted in an associative-cuing procedure (e.g., J.-Y. Chen, Chen, \& Dell, 2002; Kureta et al., 2006; Meyer, 1990, 1991; O'Séaghdha et al., 2010). In the associative-cuing task, participants memorize small sets of semantically related word pairs and then are prompted to produce the second words of the pairs (i.e., the response members) in response to the corresponding first words (i.e., the prompt members), which were presented repeatedly and randomly. In the homogeneous context, when the response members always begin with the same phonological ingredient (e.g., same initial phoneme /d/ in day, dew, and dough), the foreknowledge of the ingredient allows participants to prepare their spoken words in advance, thus facilitating their naming latency. If speakers do benefit from the foreknowledge of a phonological unit (e.g., the onset phoneme $/ d /$ ), that particular phonological unit (e.g., phoneme) is considered as the preparation unit (examples adopted from O’Séaghdha et al., 2010).

The phonological preparation unit may differ across languages in adult speakers. Native speakers of alphabetic languages such as Dutch (Meyer, 1990, 1991) and English (Jacobs \& Dell, 2014; O'Séaghdha et al., 2010) have been shown to benefit from the foreknowledge of the initial phoneme of a set of words. For nonalphabetic languages, J.-Y. Chen et al. (2002) and O'Seaghdha et al. (2010) found that native Mandarin speakers did not benefit from the shared initial phoneme in the associate-cuing task with the form preparation paradigm but showed faster response times when the initial syllable ${ }^{1}$ of the response member was shared (i.e., in this case, tone does not have to be shared). In Chinese, a syllable is usually accompanied with a lexical tone; for instance, for the syllable $m \bar{a}$ that means mother, the tone marker above the vowel $a$ denotes a high level tone and

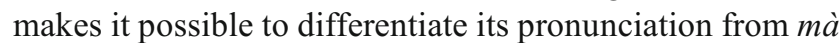
that means to scold, the tone marker here denotes a high falling tone. Native Japanese speakers also failed to benefit when the initial phoneme of response members was shared but benefited from the foreknowledge of the initial CV (consonant + vowel) called a mora (Kureta et al., 2006), referring to a timing slot for any part of a syllable other than the onset (Hyman, 1985/2003). Note that the form preparation effect should not be considered as a simple effect of repetition (see J.-Y. Chen et al., 2002; O'Séaghdha et al., 2010) but as a preparation effect as a result of mental orientation.

\section{The flexibility of preparation units}

The aforementioned cross-language differences on form preparation have been replicated not only in associative-cuing tasks but also in other tasks such as picture naming (T.-M. Chen \& Chen, 2013; O'Séaghdha et al., 2010). In addition, these findings were also consistent with the data based on speech errors (see O'Séaghdha, 2015, for review) and the studies using the masked primed naming paradigm (e.g., Verdonschot, et al., 2011; You, Zhang, \& Verdonschot, 2012). However, some recent studies suggest that the preparation unit is not immutable even within the same language. For example, Li et al. (2015) suggested that manipulation of the orthographic form cues of the stimuli might change the preparation unit in native Mandarin speakers. In an associative-cuing task with the form preparation paradigm, native Mandarin-speaking adults were asked to learn nine sets of word pairs written in morphosyllabic Chinese characters, or alphabetic pinyin symbols, a Roman alphabetic system that transcribes the pronunciation of Chinese characters. Participants did benefit from knowing the initial consonants when the words were written in Pinyin, and in contrast, such benefit did not occur when the materials were written in Chinese characters. Kureta et al. (2014) showed similar results with Japanese speakers who demonstrated significant phoneme facilitation when learning materials in Romaji (i.e., a phonetic system to write Japanese using the Latin alphabet). However, this phoneme preparation effect was not shown when materials were presented in an auditory task. Taken together, these results suggest that presenting visual materials

\footnotetext{
${ }^{1}$ Unless noted, "syllable" in the present manuscript refers to syllable without specified tonal information.
} 
in an alphabetic writing system might cue participants to use phonemes as the phonological preparation unit.

The above studies suggested speakers are flexible in selecting phonological preparation unit, probably because the orthographic cue in certain condition (e.g., presenting Chinese words in characters vs. pinyin) encouraged speakers to attend to specific phonological unit (see O'Séaghdha \& Frazer, 2014, for the attentional theory). It seems that even the temporary change of the orthographic form has clear effect on the selection of phonological preparation units. We therefore hypothesized that long-term extensive exposure to alphabetic orthographies such as pinyin or Romaji would help draw Mandarin or Japanese speakers' attention to subsyllabic units, leading to their selection of phonemes as the preparation unit even when explicit pinyin or Romaji cues are not present (note that the explicit alphabetic cues were present in both Kureta et al., 2014, and Li et al., 2015). The present study tested this hypothesis (i.e., the potential influence of long-term orthographic experience on preparation units) by examining the preparation unit in native Mandarin speakers with different orthographic experiences during the course of their learning to read. More specifically, we were interested in how the experience with pinyin versus characters would change speakers' phonological preparation unit.

\section{The influence of orthography on phonological representation}

In addition to an attentional mechanism, orthographic experience may influence phonological preparation in spoken word production via modifying speakers' grain size of phonological representation. The line of research on the influence of orthography on phonological representation has been focused on phonological awareness. There has been converging evidence to support that the acquisition of orthographic knowledge influences the development of awareness of various phonological units (see Ziegler \& Goswami, 2005, for an overview). In particular, the learning of alphabetic orthographies enhances phonemic awareness (Castles \& Coltheart, 2004; Lukatela, Carello, Shankweiler, \& Liberman, 1995; Morais, Cary, Alegria, \& Bertelson, 1979). Read, Zhang, Nie, and Ding (1986) showed that Chinese adults who had not learned pinyin performed significantly worse in adding and deleting phonemes, as compared to their counterparts who had similar education level and could read both Chinese characters and pinyin. The development of phonological awareness among native Mandarin-speaking children follows a hierarchical pattern from larger to smaller units, and there has been a consensus that their sensitivity to onset phoneme can be attributed to the experience of learning pinyin (Huang \& Hanley, 1995; McBride-Chang, Bialystok, Chong, \& Li, 2004; Shu, Peng, $\&$ McBride-Chang, 2008). The acquisition of orthographic knowledge also modifies the way children segment phonological units in spoken words (Ehri \& Ryan, 1980; Inagaki, Hatano, \& Otake, 2000). Inagaki et al. (2000) showed that Japanese children segment words from being a mixture of syllable- and mora-based to being predominantly mora-based as they acquire kana orthography, which is a mora-based writing system. In summary, the orthographic experience (e.g., alphabetic pinyin) facilitates the development of children's phonological awareness at the level that is consistent with the feature of the orthography (e.g., onset phoneme).

Given the aforementioned evidence about the role of orthographic experience in developing phonological representations, it is likely that orthographic experience would influence preparation unit in spoken word production. We suggest that the influence of orthographic experience could be a joint function of modification of phonological representation and direction of attentional resources. We further suggest that speakers can attend to a variety of phonological units depending on conditions, and the preparation of these units is mostly independent of production mechanisms. A native Mandarin speaker may prepare spoken words using syllables (with or without tone) by default. However, he may shift to prepare using onset phonemes under the conditions when pinyin cues are available (e.g., Li et al., 2015) or when the speaker has been exposed to extensive pinyin input.

In Mainland China, all children in the first 10 weeks of Grade 1 (6-7 years old) are taught to read pinyin and receive extensive pinyin practice before learning Chinese characters (Hanley, 2005). For example, the character “妈” (mother) is represented using pinyin with the spelling "mā." Its onset is the phoneme " $\mathrm{m}$," the rime is "a," and the tone is marked on top of the vowel "ā." Children are instructed to articulate a syllable by pronouncing the onset and rime separately and then combining them together (Wang \& Gao, 2011). Children are taught to pronounce the syllable $m \bar{a}$ by repeatedly spelling it as: $m-\bar{a}-m \bar{a}$. After acquiring pinyin knowledge, children then receive instruction in characters with pinyin printed on top or on their side such as 妈 or 妈 (mā). Therefore, it seems that Grade 1 children still rely on pinyin symbols to learn Chinese characters even after the 10 weeks of extensive pinyin learning. In addition, we conducted a survey about literacy instruction in primary schools, and results showed that Grade 1 children practice spelling and reading pinyin at school every day (mostly in language classes) and are given homework to write pinyin symbols throughout the academic year. Children in grades higher than Grade 1, on the other hand, do not go through such daily extensive practice in pinyin. In addition, children in higher grades than Grade 1 rely less on pinyin during reading due to their more advanced character knowledge. In the present study, we examined whether extensive alphabetic pinyin experience encourages Grade 1 children to use subsyllabic units as preparation units, 
and we hypothesize that the reliance on subsyllabic units is likely a result of the modification of children's phonological representations and attentional shift.

\section{The present study}

The associative-cuing task involves memory processes in addition to the production process (Alario, Perre, Castel, \& Ziegler, 2007; O’Séaghdha \& Frazer, 2014; Santiago, 2000). As a result, the presence or absence of an effect in an associative-cuing task may reflect something that is unique to the memory process (e.g., any strategy that facilitates memorization). In order to minimize this confound, we decided to use a picture naming task with the form preparation paradigm. The present study sought to examine the preparation unit focusing on native Mandarin-speaking children and to test whether different orthographic experiences may play a role in its development. According to the attentional account and phonological modification theory, we hypothesize that children will select the phonological unit that is consistent with the features of the orthography they have been extensively exposed to as their phonological preparation unit.

We took advantage of the language of Mandarin, whose speakers are exposed to two contrastive writing systems in the course of learning to read at young ages. Orthographic experience encompasses both orthographic knowledge/skills and orthographic exposure, and it is difficult to tease apart orthographic knowledge and exposure cleanly. For example, readers with more orthographic exposure usually have better orthographic knowledge. In the present study, both orthographic knowledge and orthographic exposure were measured among all participants. We also examined Chinese language textbooks used in the schools where we recruited the children participants. The ratio of the number of pinyin symbols versus Chinese characters in Chinese textbooks is about 1:1 in Grade 1, about 1:20 in Grade 2, and 1:80 in Grade 4. Adults are rarely exposed to pinyin and are highly proficient in character reading, and they served as the control group. Kindergartners have not been formally instructed to read any orthography, thus serving as the baseline. The comparison among these five groups allows us to examine the development of the preparation unit in natural, authentic learning contexts, enhancing the ecological validity of the study.

We predicted that kindergartners would rely on the whole tonal syllable unit as the phonological preparation unit due to the nature of Mandarin. Mandarin is a syllable-timed language with no resyllabification (Tseng, Huang, \& Jeng, 1996). In addition, kindergartners have not developed the representation of tone independent of the syllable segment, as suggested by their lack of tone awareness in previous research (e.g., Shu et al., 2008). Therefore, we predicted that tone should also be involved with the syllable segment as part of the phonological preparation unit. Grade 1 children may rely on a smaller phonological unit (e.g., onset phoneme) as the phonological preparation unit due to (a) extensive training on and exposure to pinyin, and (b) the lack of proficiency in character reading. Previous literature showed strong evidence that the atonal syllable is the default preparation unit in native Mandarinspeaking adults, and we predicted that this result would be replicated in the present study. We also predicted that Grade 4 children's performance should be similar to adults, given that both the nature of Mandarin and their extensive exposure to Chinese characters would encourage syllabic representation and preparation. Grade 2 children are in the transition period from extensive training on pinyin to characters and still need pinyin symbols to learn new Chinese characters. However, their pinyin exposure (e.g., reading and writing practice) has very much decreased compared to Grade 1. Given the much reduced pinyin exposure and the nature of Mandarin, it is possible that Grade 2 children will shift their default preparation unit back to the tonal syllable as kindergarten children do, or to the atonal syllable as skilled readers (e.g., adults) do.

\section{Experiment 1: The role of onset phoneme in phonological preparation}

This experiment was designed to investigate phonological preparation in spoken word production in literate speakers who had different orthographic experience. In particular, given that Chinese children are instructed to spell pinyin in the way of onset-rime-whole syllable, it is particularly interesting to investigate if such pinyin experience encourages children to select subsyllabic units (i.e., onset phonemes) first in phonological preparation.

\section{Method}

Participants Five groups of participants at different grade levels with normal or corrected-to-normal vision were recruited, including (a) 20 kindergarten children (nine males, mean age $=5.27$ years, $S D=.25$ ), (b) 20 Grade 1 students at 7 years of age (10 males, mean age $=7.32$ years, $S D=.30)$, (c) 18 Grade 2 students at 8 years of age (12 males, mean age $=8.33$ years, $S D=.30$ ), (d) 20 Grade 4 students at 10 years of age (seven males, mean age $=10.28$ years, $S D=.37$ ), and (e) 18 adult participants whose age ranged from 21 to 25 years (four males, mean age $=22.33$ years, $S D=.84)$. All participants were native speakers of standard Mandarin. Kindergartners were recruited from a kindergarten in Nanjing, China. School-aged children were recruited from a primary school in Tianjin, China. Adult participants were graduate students from a mid-Atlantic university but had been in the U.S. no longer than 1 month. 
Orthographic experience measures For orthographic knowledge, a pinyin reading test and a character reading test were conducted. A pinyin reading task of 48 pinyin symbols covering all possible syllable structures in Mandarin was constructed for the present study, in which all the symbols have corresponding real homophone characters. All participants were instructed to read the symbols one by one while their accuracy was recorded. In addition, a character reading task based on Li, Shu, McBride-Chang, Liu, and Peng (2012) was used, in which all participants were asked to read from the beginning and stopped when they failed to read 15 consecutive items. Both tests were paper based and used 24-point type size for each pinyin or character. For orthographic exposure, parents of the participating children as well as the adult participants completed a questionnaire about participants' weekly experience with different orthographies (i.e., pinyin, character, and others if any). The same reading tests and questionnaire were administered in the subsequent experiments involving literate participants.

The production task A simple picture naming task with the form preparation paradigm was implemented. During materials selection, 10 native Mandarin-speaking adults, 10 Grade 1 , and 10 Grade 4 children were shown a total of 30 pictures and were asked to provide the first three disyllabic names that came to mind to name a picture. Only those pictures that were named consistently using the same noun were selected as stimuli for the formal test (i.e., all participants had the final target name in their list and at least seven of them used the same target name as their first choice).

The names of the pictures consisted of three sets of disyllabic words, and the onset of the initial syllable of each set was $m$ ([m]), $h([\mathrm{x}])$, and $s h([])$, respectively. Each selected onset was used as the basis of a stimulus set that included three items. The primary manipulation of the design, context, was whether a list of pictures was homogeneous or heterogeneous. Each homogeneous list consisted of three items whose initial syllable shared the same onset, while each heterogeneous list consisted of three items that did not share any phonological information systematically in common. Within a list (for both homogeneous and heterogeneous lists), the second syllable of the picture names was not shared. Each list of pictures had three presentation blocks, in which the three picture items were presented four times (i.e., four repetitions) in a pseudorandom order so that the same picture would not be presented consecutively. Three homogeneous lists and three heterogeneous lists were formed (see Appendix A, Table 8). Both the order of the lists and the sequence of contexts, a betweensubjects factor, were counterbalanced across participants.

Procedure Each participant was tested in a quiet room. Prior to the formal experiment, all of the picture stimuli were printed out and were shown to the participants. Participants were instructed to use disyllabic words to name the pictures. If the name they provided was different from our target name, they were corrected, but these corrections occurred rarely. During the formal experiment, each trial began with a $1000 \mathrm{~Hz}$ warning tone and one fixation "+" presented at the center of the screen for $200 \mathrm{~ms}$. Six hundred ms after the offset of the tone, the picture appeared at the center of the screen for $1,500 \mathrm{~ms}$ or until a response was produced. The size of each picture was $300 \times 300$ pixels. Participants were instructed to name the picture aloud, as quickly and accurately as possible. The intertrial interval was $200 \mathrm{~ms}$. For kindergarteners, the procedure was slightly different: (1) each picture was presented for 3,000 ms or until a response was given, and (2) the interval between each list was 3 minutes ( 1 minute for other groups), and there was a 30 seconds break between each block within the same list (almost no break for other groups). In addition, a group training session was conducted before data collection for kindergarteners, in which all the children were instructed to name 32 pictures in class, including the nine target pictures and 23 fillers. After the teachers ensured that all the children were familiar with all the pictures, data collection was started.

During the formal test, the experimenter sat behind the participants and scored their naming accuracy. There were six lists in the formal test, and participants had a break between every two lists ( 3 minutes for kindergartners and 1 minute for other groups). A practice session was conducted in which all nine items were presented twice in a random order. The formal testing session began only after participants were familiar with the procedure and the materials (i.e., when participants were able to provide the correct answer of each item within $1,000 \mathrm{~ms}$ with no hesitation; (1,500 ms for kindergartners). Both the practice and formal test sessions were implemented using the DMDX software (Forster \& Forster, 2003). The reading tasks and questionnaire were administered after the picture naming task.

Data analysis All analyses were carried out in R, an opensource programming environment for statistical computing (R Development Core Team, 2008). The analyses for the picture naming task was carried out with the lme4 package (Bates, Maechler, Bolker, \& Walker, 2013) for linear mixed effects modeling (LMM) and general linear mixed effects modeling (GLMM). Only response time (RT) data for correct responses were included in analyses, and all the RT data were log-transformed in this and subsequent experiments. The RT data were removed if any of the following situations occurred: hesitation, disfluency, or the correct answer failed to trigger the voice key. RT data smaller than $200 \mathrm{~ms}$ were removed as well. Context, block and sequence were entered as fixed effects predictors in LMM. Subject and item were entered as random 
intercepts while context was entered as the slope for both intercepts (i.e., $\operatorname{LogRT} \sim$ Block $*$ Sequence $*$ Context $+(1+$ Context|Subject $)+(1+$ Context $\mid$ Item $)$. Five models were constructed to examine the context effect in each of the five groups, and all participants' data were combined in a new model in which grade level (Kindergarten, Grade 1, Grade 2 , Grade 4, and adults) was entered as a fourth fixed effect (i.e., the model is LogRT $\sim$ Grade $*$ Context $*$ Block $*$ Sequence $+(1+$ Context $\mid$ Subject $)+(1+$ Context $\mid$ Item $)$. Accuracy rates were analyzed using a similar procedure to fit GLMM.

\section{Results and discussion}

Accuracy rate All five groups achieved very high accuracy rates in the picture naming task: $95.30 \%$ for kindergartners, 98.89\% for Grade 1, 98.51\% for Grade 2, 98.98\% for Grade 4, and $99.59 \%$ for adults. After exclusions, the data that were removed from the five groups were $8.06 \%$ for kindergartners, $5.25 \%$ for Grade 1, 5.35\% for Grade 2, 3.54\% for Grade 4, and $1.77 \%$ for adults. Table 1 shows the mean naming latency and the standard deviation of each age group in each context. For brevity, only the main effects of all fixed effects predictors and the interactions between context and other predictors are reported. All child groups showed significantly lower accuracy rates than the adult group (for kindergarteners, $Z=$ $-7.70, p<.001$; for Grade 1: $Z=-2.86, p=.004$; for Grade 2, $Z=-3.70, p<.001$; for Grade 4: $Z=-2.45, p=$ $.014)$. However, context did not show any significant effect for any group in terms of accuracy rates $(p s>.10)$.
Response times We used the ANOVA approach to report the results of linear mixed effects models, using the lmerTest package (Kuznetsova, Brockhoff, \& Christensen, 2013). Combining all the five age groups, the critical item was the significant Grade $\times$ Context interaction, $F(4,82.8)=1.23$, $p=.045$. Grade also showed a significant main effect, $F(4,85.9)=26.18, p<.001$, younger groups showed overall longer RTs than older groups (kindergarteners: 992 ms; Grade 1: $724 \mathrm{~ms}$; Grade 2: $686 \mathrm{~ms}$; Grade 4: $650 \mathrm{~ms}$; adults: $630 \mathrm{~ms})$. The effect size of Grade $\times$ Context interaction increased when kindergarteners' data were excluded, $F(3$, $66.7)=6.346, p<.001$. The five models for different grade groups were run as planned. Kindergarteners did not show any significant effect $(p s>.12)$. Grade 1 children showed a significant $20 \mathrm{~ms}$ form preparation effect (i.e., faster response time in the homogeneous lists), $F(1,9.1)=5.66, p=.041$. There were no any other significant main effects or interactions ( $p$ s $>.11$ ). Grade 2 children showed a significant block effect, $F(2,3620.2)=4.08, p=.017$. Their RT was longer in the third block (Block 1: $682 \mathrm{~ms}$; Block 2: $680 \mathrm{~ms}$; Block 3: $697 \mathrm{~ms}$ ), likely a fatigue effect. No other significant main effects or interactions were shown ( $p s>.27$ ). Grade 4 children showed a significant block effect, $F(2,4102.1)=6.41, p=$ .002. Unlike Grade 2 children, their RTs were faster in later blocks (Block 1: $657 \mathrm{~ms}$; Block 2: $648 \mathrm{~ms}$; Block 3: $645 \mathrm{~ms}$ ), likely a practice effect. No other significant main effects or interactions were shown ( $p s>.10)$. Adults showed a significant block effect as well, $F(2,3756.9)=38.99, p<.001$; faster RTs in later blocks (Block 1: $648 \mathrm{~ms}$; Block 2: $623 \mathrm{~ms}$; Block 3: $618 \mathrm{~ms})$. Context did not show significant main effect,

Table 1 Descriptive data of participants' performance in Experiment 1 (the onset of the first syllable was manipulated) with mean response time ( $M$ ), error rate (E\%), standard error $(S E)$, and preparation effect

\begin{tabular}{|c|c|c|c|c|c|}
\hline Age & & Homogeneous & Heterogeneous (control) & Preparation effect (ms) & JZS Bayes factor $\left(\mathrm{BF}_{10}\right)$ \\
\hline \multirow[t]{3}{*}{ Kindergartner } & $M$ & 995 & 988 & -7 & 0.24 \\
\hline & $\mathrm{E} \%$ & .54 & .41 & & \\
\hline & $S E$ & 9.86 & 9.05 & & \\
\hline \multirow[t]{3}{*}{ Grade 1} & $M$ & 714 & 734 & $20 *$ & 2.20 \\
\hline & $\mathrm{E} \%$ & 1.34 & .88 & & \\
\hline & $S E$ & 4.00 & 4.16 & & \\
\hline \multirow[t]{3}{*}{ Grade 2} & $M$ & 690 & 682 & -8 & 0.43 \\
\hline & $\mathrm{E} \%$ & 2.00 & .98 & & \\
\hline & $S E$ & 3.91 & 3.85 & & \\
\hline \multirow[t]{3}{*}{ Grade 4} & $M$ & 650 & 650 & 0 & 0.23 \\
\hline & $\mathrm{E} \%$ & 1.20 & .83 & & \\
\hline & $S E$ & 3.11 & 2.96 & & \\
\hline \multirow[t]{3}{*}{ Adults } & $M$ & 633 & 627 & -6 & 0.28 \\
\hline & $\mathrm{E} \%$ & .62 & .21 & & \\
\hline & $S E$ & 2.96 & 2.92 & & \\
\hline
\end{tabular}

Note. $* p<.05$ 
$F(1,8.5)=.44, p=.526$. The only significant result involving context was a significant interaction between block and context, $F(2.0,3756.9)=4.43, p=.012$. Adult participants showed a $12-\mathrm{ms}$ interference effect in Blocks 1 and 2, but a 7-ms facilitative effect in Block 3 . While neither the interference nor the facilitation reached significance ( $p s>.60)$, it is indeed a large swing from 12$\mathrm{ms}$ interference to $7-\mathrm{ms}$ facilitation. Given the limited number of participants, we calculated the Bayes factor for the context main effect of each group (Rouder, Speckman, Sun, Morey, \& Iverson, 2009). See Table 1 for the JZS Bayes Factor $\left(\mathrm{BF}_{10}\right.$; the ratio of the Bayesian probability of the alternative hypothesis and the null hypothesis occurring). For significant results, a $\mathrm{BF}_{10}$ value that is 3 or above is usually considered as substantial evidence supporting for the alternative hypothesis, and one that is below 3 is at borderline. For insignificant results, a $\mathrm{BF}_{10}$ value that is one third or below is usually considered as substantial evidence supporting for the null hypothesis.

In summary, Grade 1 children showed a significant preparation effect that was consistent throughout all blocks, so it is not a simple result of repetition or practice effect. All other groups failed to show onset phoneme facilitation, suggesting that onset phoneme is not their default phonological preparation unit. Adults showed a significant Block $\times$ Context interaction, suggesting that there was a trend that speakers tended to benefit from the shared onset as the task went on. However, caution is needed to draw any conclusion since none of the three blocks showed significant context effect on their own. The attentional account could help explain this result that two blocks' experience may make adults pay more attention to the shared initial consonant, thus starting to show the trend of form preparation. Compared with children, adults may have more attentional resources and are able to attend to the characteristics of the materials more readily.

Orthographic experience Table 2 shows the descriptive statistics of the reading tasks and data on the exposure to different writing systems. For kindergartners, although there were a few hours devoted to character reading and writing, based on the report from parents and teachers, the reading for kindergartners only occurred when parents read to the children while the children were looking at the characters. The children did not recognize most of the characters they were "reading." In terms of writing, instead of writing independently, most of the time the children were copying very simple characters with fewer than five strokes (e.g., 大, 小, meaning big and small, respectively), simpler than all characters included in the reading test. In addition, the kindergartners were not aware of what pinyin is at all. Therefore, the kindergartners failed to finish the two reading tasks and we focused on the orthographic experience of the four literate groups.

With regard to the comparison among the four literate groups, for the pinyin reading task, a significant grade main effect was shown, $F(3,72)=5.88, p=.001$, and adults performed significantly better than all the three child groups $(p s<.05)$, but the child groups did not show

Table 2 Mean scores and standard deviations (in parentheses) for the two reading tasks (pinyin and Chinese character reading) and average language exposure information (hours/week) for the participants in Experiment 1 (the onset of the first syllable was manipulated)

\begin{tabular}{|c|c|c|c|c|c|}
\hline & Kindergartner & Grade 1 & Grade 2 & Grade 4 & Adults \\
\hline Pinyin reading score ${ }^{\mathrm{a}}$ & N/A & $43.80(2.93)$ & $44.89(2.11)$ & $43.45(2.74)$ & $46.44(1.45)$ \\
\hline Character reading score ${ }^{\mathrm{b}}$ & N/A & $72.00(27.10)$ & $79.44(26.65)$ & $123.25(12.30)$ & $139.78(3.23)$ \\
\hline \multicolumn{6}{|c|}{ Language exposure (reading) ${ }^{\mathfrak{c}}$} \\
\hline Pinyin & 0 & $3.58(1.80)$ & $0.90(0.71)$ & $0.40(0.56)$ & $0(0)$ \\
\hline Character & $2.12(1.71)$ & $8.23(4.12)$ & $13.08(1.29)$ & $22.25(6.88)$ & $26.03(16.00)$ \\
\hline English & 0 & $2.90(2.06)$ & $3.42(1.02)$ & $6.75(3.47)$ & $13.19(9.45)$ \\
\hline \multicolumn{6}{|c|}{ Language exposure (writing) $^{\mathrm{c}}$} \\
\hline Pinyin & 0 & $1.65(0.93)$ & $0.97(0.36)$ & $0.40(0.57)$ & $0(0)$ \\
\hline Character & $1.80(2.22)$ & $2.97(1.38)$ & $5.78(1.36)$ & $10.65(8.43)$ & $4.06(4.17)$ \\
\hline English & 0 & $0.15(0.50)$ & $0.22(0.39)$ & $4.15(2.54)$ & $3.50(4.69)$ \\
\hline \multicolumn{6}{|c|}{ Language exposure (typing) ${ }^{\mathrm{c}}$} \\
\hline Pinyin & 0 & $0(0)$ & $0(0)$ & $0.35(0.76)$ & $9.64(7.82)$ \\
\hline Character & 0 & $0(0)$ & $0(0)$ & $0(0)$ & $0(0)$ \\
\hline English & 0 & $0(0)$ & $0(0)$ & $0.15(0.67)$ & $3.55(2.93)$ \\
\hline
\end{tabular}

a The maximum possible pinyin reading score is 48

$\mathrm{b}$ The maximum possible character reading score is 150

c The unit of language exposure is hours per week 
significant differences among each other. For character reading, a significant grade main effect was also shown, $F(3,72)=$ 50.96, $p<.001$. Adults' score was significantly better than Grade 1 and Grade 2 children $(p s<.001)$ and was better than Grade 4 ( $p=.064)$. Grade 4 children's score was significantly better than that of Grade 1 and Grade 2 children ( $p s<.001)$. In terms of the pinyin:character exposure ratio in reading, a significant grade main effect was shown, $F(3,72)=82.24, p$ $<.001$. Grade 1's relative pinyin exposure was significantly longer than that of the other three groups $(p s<$ .001 ), while no significant difference was shown among the other three groups. Finally, for the pinyin:character exposure ratio in writing, again, a significant grade main effect was shown, $F(3,72)=29.94, p<.001$. Grade 1 's relative pinyin exposure was significantly longer than that of all the other three groups ( $p$ s <.001). No significant difference was shown in any other pairwise comparison. All children rarely typed pinyin, whereas adults spent many hours (mean $>9$ hours per week) in typing, thus making the comparison of typing obvious. Overall, Grade 1 children showed the more relative pinyin exposure $($ mean $=.54)$ than all other groups $(p s<.05$; for Grade 2, mean = .10; for Grade 4, mean $=.04$; for adults, mean $=.33$ ). Note that, for adults, all pinyin exposure was from typing, and it made their relative pinyin exposure significantly more than Grades 2 and 4 children $(p s<.01)$. Previous literature has shown that if participants were required to type (not speak) in a phonology-based input method, they were able to show the form preparation effect at the subsyllabic level (J.-Y. Chen \& Li, 2011). The experience of typing alphabetic orthographies may encourage participants to rely on subsyllabic units when typing but not when speaking (i.e., modality dependent). However, the fact that adults showed a trend of preparation in the last block might be related to the extensive pinyin typing procedure.

Given that only Grade 1 children showed an onset phoneme preparation effect while all other groups did not show such an effect (not even a trend with the same direction), and that the only factor that significantly differed for Grade 1 children compared to all other literate groups was pinyin exposure, we conducted a new model to examine whether relative pinyin exposure influenced the form preparation effect (note that kindergartners were not included given their minimal orthographic experience in both writing systems). We used relative pinyin exposure (i.e., pinyin:character exposure ratio) instead of absolute pinyin exposure because characters encourage whole syllable representation. For example, high absolute pinyin exposure but even higher absolute character exposure may eliminate the influence of pinyin. Relative pinyin exposure (RPE), block, sequence, and context were entered as fixed effects in the new model, while subject and item still served as two random intercepts and context served as the random slope. A significant RPE $\times$ Context interaction was shown, $F(1,53.0)=9.80, p=.003$. Participants with more relative pinyin exposure in general showed larger preparation effects (see Fig. 1). Although the current data showed a linear relationship between relative pinyin exposure and form preparation effect size, caution is needed when explaining the results. The correlation was weak $(r=.32)$, and orthographic experience was confounded with age or grade level (e.g., only Grade 1 children were required to do homework about pinyin). Therefore, we suggest that it is more appropriate to use children's grade level in studying the preparation effect, but pinyin exposure likely contributes to the group differences.

\section{Experiment 2: The role of atonal syllable in phonological preparation}

The previous literature suggests that the phonological preparation unit is the syllable without specified tone (i.e., the atonal syllable) in Mandarin-speaking literate adults. The current experiment was designed to address whether syllable regardless of tonal information (i.e., atonal syllable) is indeed selected as the phonological preparation unit among the groups who failed to show onset facilitation in our Experiment 1.

\section{Method}

Participants Five groups of participants were recruited, including (a) 16 kindergartners (eight males, mean age $=5.17$ years, $S D=.30$ ), (b) 18 Grade 1 students (seven males, mean age $=7.29$ years, $S D=.30)$, (c) 18 Grade 2 students $(12$ males, mean age $=8.31$ years, $S D=.32$ ), (d) 20 Grade 4 students (eight males, mean age $=10.33$ years, $S D=.30$ ), and (e) 18

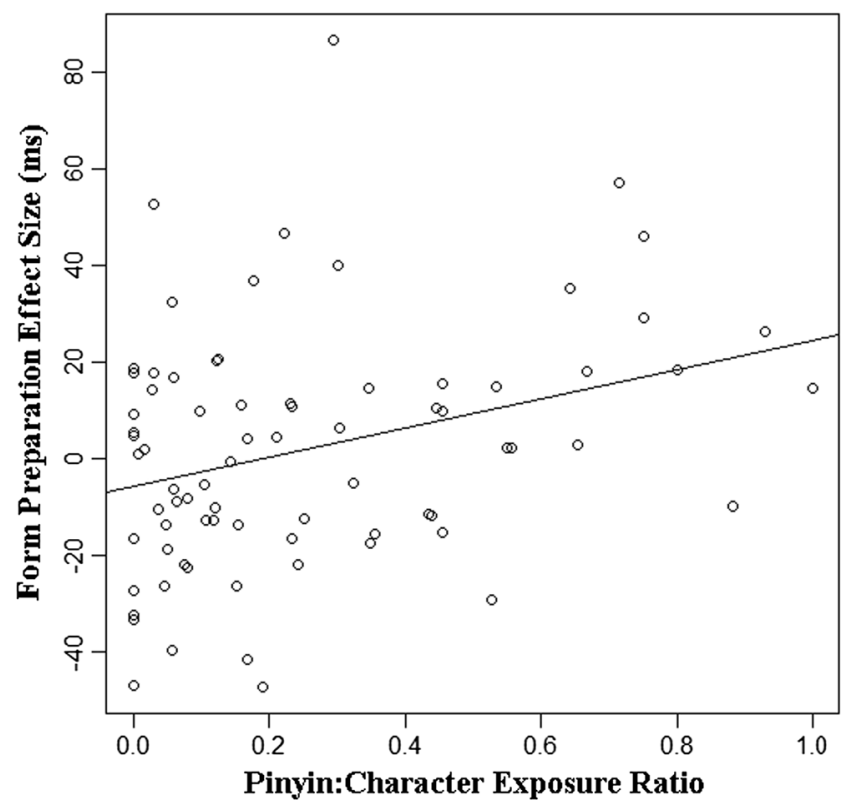

Fig. 1 The effects of relative pinyin exposure on speakers' form preparation effect in Experiment 1 
adult participants (three males, mean age $=22.18$ years, $S D=$ 1.84). The kindergartners and adults were from the same subject pools as those in Experiment 1, but all the school-aged children were recruited from a different primary school from that in Experiment 1. Both schools were located in Tianjin, China, and the same curriculum was employed in the two schools.

Procedure For the picture naming task, the design and procedure were same as those in Experiment 1, except that the shared phonological ingredient in the homogeneous list was the initial tonal syllable. The pinyin symbols of the three initial syllable segments are mao, shan, and he (see Appendix A, Table 9 for the full stimuli). The reading tests and questionnaire were also same as those used in Experiment 1.

\section{Results and discussion}

The procedure of data exclusion and analyses were same as that in Experiment 1. All four groups achieved very high accuracy rates in the picture naming task: $96.18 \%$ for kindergartners, $99.43 \%$ for Grade 1, 98.12\% for Grade 2, $99.00 \%$ for Grade 4 , and $99.71 \%$ for adults. As a result of exclusions, the data that were removed from the four age groups were: $8.25 \%$ for kindergartners, $5.27 \%$ for Grade 1, 7.44\% for Grade 2, $5.58 \%$ for Grade 4 , and $1.87 \%$ for adults. Table 3 shows the mean naming latency and the standard deviation of each age group. Again, for brevity, only the main effects of all fixed effects predictors and the interactions between context and other predictors are reported. All child groups showed lower accuracy rate than the adult group (for kindergarteners, $Z=$ $-7.81, p<.001$; for Grade $1: Z=-1.79, p=.073$; for Grade 2, $Z=-5.53, p<.001$; for Grade $4: Z=-3.57, p<.001)$. Only the kindergartners showed significantly lower accuracy rate in the homogeneous condition $(Z=-3.20, p=.001)$ relative to the control condition. None of the other four groups showed any significant context main effect or interactions with other factors in terms of accuracy rates ( $p s>.10)$.

Response times Combining all the five groups, the critical result was a significant Grade $\times$ Context interaction, $F(4.0$, $79.4)=15.58, p<.001$, with grade also showing a significant main effect, $F(4,80)=38.69, p<.001$, as younger groups showed overall longer RTs than older groups (kindergarteners: 989 ms; Grade 1: 719 ms; Grade 2: 705 ms; Grade 4: 677 ms; adults: $595 \mathrm{~ms}$ ). The five models for different grade groups were run. Kindergartners showed significantly longer RT (73 ms more) in homogeneous condition, $F(1.0,13.5)=$ $32.29, p<.001$. The atonal syllable interference effect was different across blocks, $F(2.00,3124.28)=3.10, p=.045$, being stronger in the first two blocks (Block 1: $87 \mathrm{~ms}$ inhibition; Block 2: $84 \mathrm{~ms}$ inhibition; $p \mathrm{~s}<.001)$ than in the third block (46 ms inhibition; $p=.063$ ). Grade 1 children showed a significant $25 \mathrm{~ms}$ interference effect in the homogeneous context, $F(1,13.6)=4.93, p=.044$. There were no other main effects or interactions ( $p s>.47)$. For Grade 2 children, context did not show significant main effect or interaction with sequence $(p s>.30)$. Yet there was a significant interaction between context and block, $F(2,3538)=3.39, p=.034$. In Block 1, a trend of inhibition ( $8 \mathrm{~ms})$ was shown for the

Table 3 Descriptive data of participants' performance in Experiment 2 (the initial atonal syllable was manipulated) with mean response time ( $M)$, error rate $(\mathrm{E} \%)$, standard error $(S E)$, and preparation effect

\begin{tabular}{|c|c|c|c|c|c|}
\hline Age & & Homogeneous & Heterogeneous (control) & Preparation effect (ms) & JZS Bayes factor $\left(\mathrm{BF}_{10}\right)$ \\
\hline \multirow[t]{3}{*}{ Kindergartener } & $M$ & 1026 & 953 & $-73 * * *$ & 595.7 \\
\hline & $\mathrm{E} \%$ & 5.26 & 2.38 & & \\
\hline & $S E$ & 9.24 & 7.60 & & \\
\hline \multirow[t]{3}{*}{ Grade 1} & $M$ & 732 & 707 & $-25^{*}$ & 1.71 \\
\hline & $\mathrm{E} \%$ & .87 & .26 & & \\
\hline & $S E$ & 4.14 & 3.75 & & \\
\hline \multirow[t]{3}{*}{ Grade 2} & $M$ & 703 & 708 & 5 & 0.26 \\
\hline & $\mathrm{E} \%$ & 1.39 & .88 & & \\
\hline & $S E$ & 3.85 & 3.96 & & \\
\hline \multirow[t]{3}{*}{ Grade 4} & $M$ & 665 & 689 & $24 *$ & 3.71 \\
\hline & $\mathrm{E} \%$ & 2.36 & 1.39 & & \\
\hline & $S E$ & 3.29 & 3.38 & & \\
\hline \multirow[t]{3}{*}{ Adults } & $M$ & 586 & 604 & $18^{*}$ & 3.63 \\
\hline & $\mathrm{E} \%$ & .46 & .10 & & \\
\hline & $S E$ & 2.39 & 2.33 & & \\
\hline
\end{tabular}

Note. $* p<.05 . * * * p<.001$ 
homogeneous context; in Block 2, a trend of facilitation was shown $(11 \mathrm{~ms})$; in Block 3 , the difference between the contexts was only $1 \mathrm{~ms}$ facilitation. None of the above differences reached significance $(p s>.40)$. For Grade 4 children, a significant context main effect was shown, $F(1,13.4)=7.19, p=$ .018. Grade 4 children showed significantly faster RTs in the homogeneous context. All other main effects and interactions did not reach significance $(p s>.20)$. Adults showed a significant block effect, $F(2.0,3752.5)=66.12, p<.001$. Their RTs were faster in later blocks (Block 1: 616 ms; Block 2: 590 ms; Block 3: $581 \mathrm{~ms}$ ), likely a practice effect. For the critical variable, context, a significant facilitative effect was shown, $F(1.0,18.6)=5.82, p=.026$. Context did not show significant interactions with any other variables ( $p \mathrm{~s}$ $>$.27). Again, we calculated the Bayes factor of the Context main effect for each group (see Table 3 ).

Orthographic experience Table 4 shows the descriptive statistics of the reading tasks and the data on the exposure to different writing systems. Again, kindergartners spent a few hours on character reading and writing, but it was more like "watching" and "copying" than "reading" and "writing"; therefore, we focused on the comparison among the four literate groups. For the pinyin reading task, a significant grade main effect was shown, $F(3,70)=5.88, p=.001)$. Adults performed significantly better than Grade $4(p<.001)$, but the child groups did not show any significant difference ( $p$ s $>.08$ ). For character reading, a significant grade main effect was also shown, $F(3,70)=67.6, p<.001$, as an older group score was always better than a younger one $(p s<.01)$. In terms of the pinyin:character exposure ratio in reading, a significant grade main effect was shown, $F(3,70)=56.12, p<.001$. Grade 1's relative pinyin exposure was significantly greater than that of all other three groups ( $p s<.001)$. Finally, for the pinyin:character exposure ratio in writing, again, a significant grade main effect was shown, $F(3,72)=15.58, p<.001$. Grade 1's relative pinyin exposure was significantly longer than all other groups $(p s<.001)$. Grade 2's relative pinyin exposure was also significantly longer than that of Grade 4 and adults $(p s<.01)$. Again, children rarely type, which made the comparison in typing obvious.

Combining the four literate groups and using relative pinyin exposure (RPE) to replace group level as a fixed effect, an RPE $\times$ Context interaction was shown again, $F(1.0,69.4)=$ $6.52, p=.013$. However, the correlation between RPE and form preparation effect was still low $(r=-.31)$. In addition, though both Grade 4 children and adults showed significant form preparation effect, their RPE was the lowest and second highest in the four groups, respectively (mean $=.04$ for Grade 4 , mean $=.29$ for adults; Grade 1 children still had the highest $\mathrm{RPE}$, mean $=.42$; mean $=.12$ for Grade 2 ). As a result, while pinyin experience may contribute to the difference, it is more appropriate to examine the preparation effect according to grade level.

The significant atonal syllable facilitation in adults was consistent with findings in previous literature, and children as young as Grade 4 had already shown the same phonological

Table 4 Mean scores and standard deviations (in parentheses) for the two reading tasks and average language exposure information (hours/week) for the participants in Experiment 2 (the initial atonal syllable was manipulated)

\begin{tabular}{|c|c|c|c|c|c|}
\hline & Kindergartner & Grade 1 & Grade 2 & Grade 4 & Adults \\
\hline Pinyin reading score ${ }^{\mathrm{a}}$ & N/A & $44.33(3.77)$ & $43.78(3.17)$ & $42.15(3.84)$ & $46.50(1.34)$ \\
\hline Character reading score ${ }^{\mathrm{b}}$ & N/A & $66.67(25.61)$ & 90.78 (17.99) & $121.85(12.20)$ & $139.44(3.71)$ \\
\hline \multicolumn{6}{|c|}{ Language exposure (reading) ${ }^{\mathrm{c}}$} \\
\hline Pinyin & 0 & $3.72(3.04)$ & $1.38(1.34)$ & $0.57(0.57)$ & $0(0)$ \\
\hline Character & $2.37(1.67)$ & $8.38(3.14)$ & $12.74(5.59)$ & $26.65(11.11)$ & $34.47(18.76)$ \\
\hline English & 0 & $3.36(1.84)$ & $3.78(3.79)$ & $9.57(4.59)$ & $9.75(8.10)$ \\
\hline \multicolumn{6}{|c|}{ Language exposure (writing) ${ }^{\mathrm{c}}$} \\
\hline Pinyin & 0 & $1.00(0.59)$ & $0.95(0.84)$ & $0.08(0.28)$ & $0(0)$ \\
\hline Character & $1.47(1.13)$ & $3.27(1.02)$ & $6.91(7.12)$ & $18.35(7.14)$ & $8.69(8.67)$ \\
\hline English & 0 & $0.12(0.26)$ & $1.37(1.99)$ & $4.025(1.87)$ & $5.05(8.35)$ \\
\hline \multicolumn{6}{|c|}{ Language exposure (typing) ${ }^{c}$} \\
\hline Pinyin & 0 & $0(0)$ & $0.13(0.36)$ & $0.94(1.40)$ & $12.56(13.78)$ \\
\hline Character & 0 & $0(0)$ & $0(0)$ & $0(0)$ & $0(0)$ \\
\hline English & 0 & $0(0)$ & $0(0)$ & $0.17(0.67)$ & $3.96(3.09)$ \\
\hline
\end{tabular}

a The maximum possible pinyin reading score is 48

$\mathrm{b}$ The maximum possible character reading score is 150

c The unit of language exposure is hours per week 
preparation pattern as adults. Unexpectedly, Grade 1 children showed a significant interference effect. Given that only a shared initial consonant benefited their phonological preparation in Experiment 1, it is surprising to see the interference effect in Experiment 2, where additional phonological content was shared (i.e., rime). This result is inconsistent with previous findings that shared consecutive beginning phonological content led to larger preparation effect sizes (Meyer, 1991). A potential explanation is that Grade 1 children may represent and encode rime and tone as an integral unit, and a shared rime with different tone may lead to difficulty in the process of articulation, or in the process of selecting the target rime + tone unit as a result of a miscuing effect from the previous trial on the current trial (see a similar interpretation in Sevald \& Dell, 1994; Sullivan, 1999). In addition, the difficulty at the articulatory locus canceled the onset phoneme facilitation. In pinyin instruction, children are taught to pronounce a syllable in the order of onset - (rime + tone) - whole syllable (e.g., spell $m \bar{a}$ by repeatedly spelling it as $m-\bar{a}-m \bar{a}$ ), so this instruction may also play a role. Another possibility is that the syllable functions in a different way from phonemes. At least for Mandarin, syllables may not be a simple sum of multiple phonemes. Once it is available and it draws Grade 1 children's attention, it influences preparation in a negative way, likely due to the potential lexical activation and competition among syllable neighbors.

Kindergartners also showed significant atonal syllable interference effect in both accuracy rate and RT analysis. Given that kindergartners did not show any onset effect in Experiment 1, and that they may have not developed the ability to separate onset and rime (i.e., lack of onset awareness; see Shu et al., 2008), the mechanism underlying the interference effect for kindergartners would be different from that for Grade 1 children. It is likely that kindergartners processed syllable and tone as an integral unit, and the shared syllable with different tone led to difficulty of articulation, or a miscuing effect when selecting the tonal syllable. In other words, tone seems to be attached to rime for Grade 1 children, but could be attached to the whole syllable for kindergartners. Grade 2 children did not show significant context effect or any clear trend over blocks, rather, different patterns of the context effect were shown in each block. Therefore, at least atonal syllables did not serve as the default preparation unit in Grade 2 children.

\section{Experiment 3: The role of tonal syllable in literate speakers}

Experiments 1 and 2 showed that onset phonemes and atonal syllables might be the default phonological preparation unit in Grade 1 children and skilled readers (including Grade 4 children and adults), respectively. However, kindergartners and
Grade 2 children failed to show the form preparation effect in either experiment. The current experiment was designed to address the possibility that the tonal syllable could be the preparation unit for these two groups of children.

\section{Method}

Participants Sixteen different kindergartners (eight males, mean age $=5.38$ years, $S D=.28$ ) and 18 Grade 2 (nine males, mean age $=8.33$ years, $S D=.32$ ) were recruited from same subject pools as in Experiment 2. None of the participants participated in previous experiments.

Procedure The design and procedure used to select the stimuli for the picture naming task were similar to the one in Experiment 2. Ten adults and 10 Grade 2 children were asked to name the candidate stimuli for Experiment 3 using disyllabic words, resulting in nine pictures being selected as final stimuli (see Appendix A, Table 10 for full stimuli). The pinyin symbols of the three initial syllables and tones are xiàng, shù, and hé, respectively. Note that although the initial syllables were shared, the initial characters were different in a homogeneous list, thus avoiding lexical overlap. The reading tests and questionnaire were same as those used in previous experiments.

\section{Results and discussion}

The accuracy rate of the picture naming task was $95.54 \%$ for kindergartners and $98.35 \%$ for Grade 2 children. The total percentage of data loss due to data exclusions was $11.8 \%$ for kindergartners and $3.75 \%$ for Grade 2 children. Table 5 shows their mean accuracy rate, mean naming latency, and the standard deviation in each of the two context conditions. The Bayes factor of the context main effect for each group was also included. Although no significant effect was shown for accuracy $(p s>.10)$, kindergartners showed significantly shorter RT in the homogeneous condition, $F(1.00,13.21)=$ $32.59, p<.001$. There was also a complicated three-way interaction among block, sequence, and context, $F(2.00$, 2993.07) $=3.66, p=.026$, but the facilitation applied to all the Block $\times$ Sequence combinations (all $>40 \mathrm{~ms}$ ), suggesting that the kindergarteners used tonal syllable as their preparation unit. Kindergarteners have been shown to be unable to represent, think of, or manipulate sounds in subsyllabic units (e.g., Shu et al., 2008). Consequently, for these kindergartners, the tonal syllable is likely to be treated as the first and best candidate in the initial stage of word form processing in spoken word production.

Grade 2 children did not show any significant effects in accuracy rate $(p s>.25)$ either, but they showed a significant $29 \mathrm{~ms}$ form preparation main effect in RT as well, $F(1.0,14.7)$ $=7.94, p=.013$. There was also a significant block main 
Table 5 Descriptive data of participants' performance in Experiment 3 (the initial tonal syllable was manipulated) with mean response time ( $M$ ), error rate $(\mathrm{E} \%)$, standard error $(S E)$, and preparation effect

\begin{tabular}{|c|c|c|c|c|c|}
\hline Age group & & Homogeneous & Heterogeneous (control) & Preparation effect (ms) & JZS Bayes factor $\left(\mathrm{BF}_{10}\right)$ \\
\hline \multirow[t]{3}{*}{ Kindergartener } & $M$ & 955 & 1,030 & $75 * * *$ & 622.30 \\
\hline & $\mathrm{E} \%$ & 2.36 & 6.08 & & \\
\hline & $S E$ & 12.50 & 12.55 & & \\
\hline \multirow[t]{3}{*}{ Grade 2} & $M$ & 728 & 757 & $29 *$ & 4.85 \\
\hline & $\mathrm{E} \%$ & 1.34 & 1.95 & & \\
\hline & $S E$ & 3.64 & 3.65 & & \\
\hline
\end{tabular}

Note. $* p<.05 . * * * p<.001$

effect, $F(2.0,3262.6)=5.18, p=.006$. Participants showed faster RTs in later blocks (Block 1: $750 \mathrm{~ms}$; Block 2: $737 \mathrm{~ms}$; Block 3: $741 \mathrm{~ms}$ ), likely a practice effect. There was also a significant Block $\times$ Context interaction, $F(2.0,3262.6)=8.86$, $p<.001$. The syllable facilitation effect was not significant in Block 1 (3 ms; $p=.807)$, but was significant in Block 2 (52 $\mathrm{ms} ; p<.001)$ and Block 3 (33 ms; $p=.007)$. The descriptive statistics of the reading tasks and the data on the exposure to different writing systems in terms of reading, writing, and typing (hourly/week) are shown in Table 6. Taken together, these results suggest that Grade 2 children overall could select the tonal syllable as their phonological preparation unit, after some exposure (i.e., the preparation effect was only significant in later two blocks). During the transitional period, Grade 2 children may have difficulty settling on a fixed default

Table 6 Mean scores and standard deviations (in parentheses) for the two reading tasks and average language exposure information (hours/ week) for the participants in Experiment 3 (the initial tonal syllable was manipulated)

\begin{tabular}{lll}
\hline & Kindergartner & Grade 2 \\
\hline Pinyin reading score $^{\mathrm{a}}$ & $\mathrm{N} / \mathrm{A}$ & $42.83(3.36)$ \\
Character reading score $^{\mathrm{b}}$ & $\mathrm{N} / \mathrm{A}$ & $97.78(17.97)$ \\
Language exposure (reading) $^{\mathrm{c}}$ & & \\
$\quad$ Pinyin & 0 & $1.09(0.78)$ \\
$\quad$ Character & $1.94(1.46)$ & $11.17(4.56)$ \\
$\quad$ English & 0 & $2.62(1.86)$ \\
Language exposure (writing) $^{\mathrm{c}}$ & & \\
$\quad$ Pinyin & 0 & $0.51(0.95)$ \\
Character & $1.31(1.00)$ & $4.37(2.58)$ \\
$\quad$ English & 0 & $0.64(1.27)$ \\
Language exposure (typing) & & \\
Pinyin & 0 & $0.13(0.36)$ \\
Character & 0 & $0(0)$ \\
English & 0 & $0(0)$ \\
\hline
\end{tabular}

a The maximum possible pinyin reading score is 48

$\mathrm{b}$ The maximum possible character reading score is 150

c The unit of language exposure is hours per week phonological preparation unit (even tonal syllable did not benefit Grade 2 children in the first block). However, based on the attentional account, we suggest that with increasing attentional resources, children should be able to learn to attend to the characteristics of materials and adapt to the demands of the form preparation task, thus leading to the facilitation effect in later blocks.

\section{General discussion}

The present study examined the influence of orthographic experience on the development of the phonological preparation unit in native Mandarin speakers. Kindergartners and Grade 2 children only showed preparation effects when the initial syllable + tone was shared across target spoken words, whereas Grade 1 showed an onset phoneme preparation effect, and Grade 4 and adults showed an atonal syllable preparation effect (see Fig. 2 for a summary of these critical findings). These findings offer novel evidence that the primary

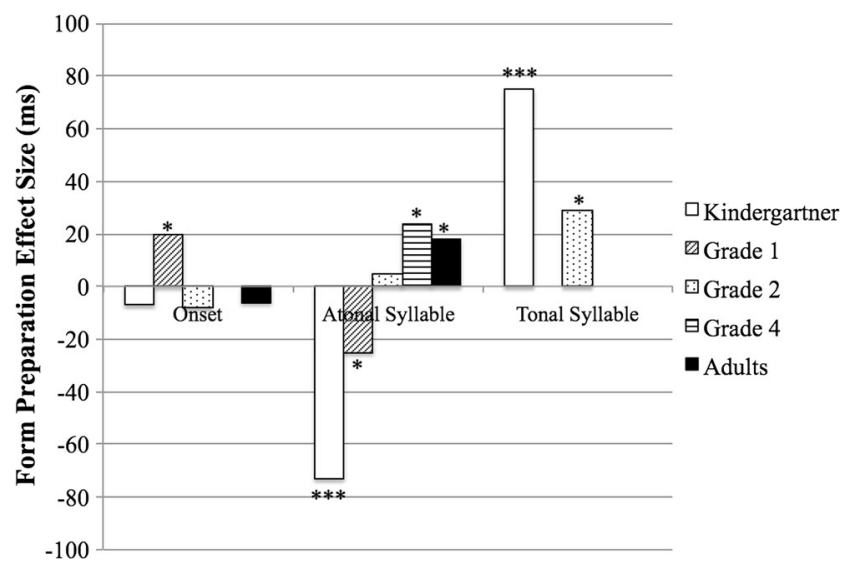

Fig. 2 The form preparation effect size across all the five groups in three experiments, where the onset (Experiment 1), the initial atonal syllable (Experiment 2), and the initial tonal syllable (Experiment 3) was manipulated, respectively. Positive numbers refer to facilitation, whereas negative numbers refer to inhibition. $* p<.05$. *** $p<.001$. Only kindergartners and Grade 2 children were recruited in the tonal syllable condition 
phonological unit in the preparation of spoken words is influenced by speakers' orthographic experience, including experience with different orthographic forms.

Overall, the group differences in our study support the flexibility of phonological preparation unit, that the first selectable unit in preparation of spoken word production is not immutable throughout the life span. Previous literature that showed reliable cross-language differences suggests that the default preparation unit of a language in adults may be largely dependent upon the nature of a language (e.g., syllable timed for Mandarin), and there is some flexibility depending on the task demands in spoken word production. The temporary change of the preparation unit under certain task demand could be explained by the attentional theory (O'Séaghdha \& Frazer, 2014). In O'Séaghdha and Frazer (2014), in both picture naming and word naming tasks, the preparation effect was shown among native English speakers even when lists included an exception word (i.e., a word that does not share the initial phoneme with other response members) in the homogeneous list. However, this effect was not shown in the associative naming task in which the form preparation paradigm was used. Compared with the picture naming and word naming task, the associative cuing task is very resource intensive and demanding - it requires decoding the information of the prompt members first then retrieving the response members. Therefore, the absence of the preparation effect for the "odd one out" list (i.e., the homogeneous list with one exception word) in the associative cuing task may be a result of lacking attentional resources. Speakers are able to attend to the shared initial consonant in less demanding tasks despite of the exception word, thus benefiting from the shared unit; however, in a challenging associative naming task, it is difficult to allocate the attentional resources to such a unit and benefit from it. In addition, the preparation effect in both the picture-naming and word-naming tasks was larger in the second block than in the first block, further supporting the attentional account - preparation gets stronger with more experience. In other words, more attentional resources are available in a later block so that it helps speakers overcome the difficulty of having an exception item.

The findings from our three sets of experiments suggest that the attentional orientation and the likely modification of the grain size of phonological representations may jointly contribute to the developmental changes in phonological preparation in Mandarin. We illustrated the process of the modification of phonological representations and attentional shift across different age groups along with the change of orthographic experience in Table 7.

\section{The preparation from phoneme, atonal syllable, and tonal syllable}

In the present study, even kindergartners who may have the least attentional resources and capacity showed a tonal syllable preparation effect, suggesting that the tonal syllable is an efficient unit in phonological preparation. Prior to first grade, children were only at chance levels in detecting onset phonemes (Shu et al., 2008) and failed to benefit from onset phoneme preparation in the present study (our Experiment 1). With minimal literacy instruction and the tonal syllable based speech input, the kindergartners are likely to represent and think of phonological information in syllable unit, as depicted in the phonological representation column in Table 7. Likewise, for preparation of spoken words by the kindergarteners, only preactivating the whole syllable + tone unit together is strong enough to facilitate preparation, see the column of production preparation unit in Table 7 .

From first grade on, children have developed the awareness of different phonological units, including onset phoneme, tone, and syllable (see Shu et al., 2008). In addition, extensive pinyin experience may also encourage Grade 1 children to attend to onset phonemes separately from the whole syllable, so that they can represent onset separately from the whole syllable, and are more likely to attend to onsets in phonological preparation. In contrast, Grade 4 children and adults are more likely to attend to syllable and use syllable as a primary and default preparation unit due to their extensive character experience. Note that skilled readers such as Grade 4 and adults have indeed mastered phonemic representations and are able to manipulate phonemic sounds. Furthermore, adults and Grade 4 children should have more attentional resources and capacity than Grade 1 children. If Grade 1 children could allocate enough attention to onset phonemes, so that the preactivation of

Table 7 The developmental trajectory of native Mandarin speakers' phonological representation and phonological preparation in spoken word production

\begin{tabular}{lllll}
\hline & Grade level & Orthographic experience (reading \& writing) & Phonological representation unit & Production preparation unit \\
\hline Stage 1 & Kindergarten & Preliterate & Syllable & Tonal syllable \\
Stage 2 & Grade 1 & Extensive alphabetic Pinyin exposure & Onset, rime, tone, syllable & Onset phoneme \\
Stage 3 & Grade 2 & $\begin{array}{c}\text { More morphosyllabic character exposure, } \\
\text { less pinyin exposure }\end{array}$ & Onset, rime, tone, syllable & $\begin{array}{c}\text { Not fixed; may temporarily use } \\
\text { tonal syllable }\end{array}$ \\
Stage 4 & Grade 4 \& up & Dominant, extensive character exposure & Onset, rime, tone, syllable & Atonal syllable \\
\hline
\end{tabular}


onset phonemes facilitates preparation, Grade 4 children and adults should at least have the same capacity to do so. However, this was not the case in Experiment 1. Therefore, we argue that the attentional orientation is not just a matter whether speakers are capable of doing this but rather whether the speakers orient their attention to a certain unit as a default. All speakers from Grade 1 on are able to attend to onset; however, the long-term character experience encourages skilled readers to orient their attention to syllable unit by default. Interestingly, extensive pinyin exposure in typing did not make adults orient their attention more to the phoneme unit at the initial stage of phonological encoding, although onset phoneme has been shown to be the preparation unit in word typing in J.-Y. Chen and Li (2001). One possibility is Grade 1 children are often required to spell out the pinyin symbols when reading, during which the onset and rime + tone are explicitly separated, thus making the subsyllabic unit very salient. In contrast, typing does not require adults to do so. In addition, the time adults spent on typing pinyin is much less than that they spent on reading characters (see both Tables 1 and 2), so that the phoneme-based phonological processing experience in pinyin typing is not strong enough to influence oral language production. Future research may be conducted to test this hypothesis.

For Grade 2 children, they also have phonological representations of different units, but only preactivating of the whole tonal syllable is sufficient to facilitate preparation. Note that even shared tonal syllables did not benefit Grade 2 children in the first block. However, Grade 2 children adapted tonal syllables as the preparation unit quickly in later blocks. Note that such a pattern (i.e., significant facilitation in later blocks, which led to an overall context main effect) only occurred in Experiment 3 but not in Experiments 1 or 2, suggesting that the tonal syllable is a more efficient candidate as a preparation unit compared to phonemes or atonal syllables. It is possible that Grade 2 children are in the transition period from relying on phonemes to atonal syllables as the default preparation unit. Grade 2 children's phonological representation of the primary unit in phonological preparation may not have been well formed so that they may rely on tonal syllables, the most salient unit to prepare spoken words and facilitate the completion of a production task. Again, given the significant interaction between context and block and the insignificant form preparation effect in the first block, caution is needed when treating tonal syllable as the phonological preparation unit. In general, there might be no default preparation unit for Grade 2 children, and tonal syllable is simply more salient than other units, so that it is easier to be adapted in certain contexts (e.g., shared tonal syllable in a series of pictures). We suggest that tonal syllable may be better considered as a temporary preparation unit in Grade 2 children. It is possible that, in addition to Grade 2, some native Mandarin speakers who do not have a fixed default preparation unit may also quickly adopt tonal syllable as a temporary preparation unit when it is available to facilitate production.

Note that some previous literature has investigated the role of orthography in phonological preparation related to the effect of grapheme-phoneme correspondence (e.g., the rime of light and byte sounds same but are spelt differently), and showed that the different spellings of the same sound had no effect on form preparation (Alario et al., 2007; Damian \& Bowers, 2009; Roelofs, 2006). However, the present study, together with limited recent studies (e.g., Li et al., 2015; Kureta et al., 2014) addressed the role of orthography on the grain size of phonological preparation. Collectively, findings suggest that the exposure to different orthographic forms (e.g., alphabetic vs. morpho-syllabic) indeed influences phonological preparation, no matter when the orthography directly serves as a cue in the language production task (e.g., Li et al., 2015), or when the influence stems from the long-term exposure to a specific orthographic form (the present study).

\section{The role of tone and atonal syllable inhibition}

J.-Y. Chen et al. (2002) found that shared tone alone would not facilitate preparation, but compared with shared atonal syllable, tonal syllables showed significantly larger preparation effect. Therefore, tone is an important component in phonological preparation in adults, but tone may not function similarly as segmental syllable, likely due to the fact that it is a suprasegmental feature/metrical property. Grade 4 children and adults are able to represent tone independently, and may treat it as a supplementary component in phonological preparation. Given that only tonal syllables led to significant preparation effects for Grade 2 children, it seems that tone is integrated in the phonological preparation unit for this group of children. In terms of preparation, tone may be as important as segmental syllable.

The atonal syllable inhibition in kindergartners and Grade 1 children was unexpected. As mentioned earlier, for Grade 1 children in particular, the interference even canceled off the onset phoneme facilitation. One possibility is the integrity of rime and tone, so that having shared rime but different tones leads to difficulty and interference in the process of articulation, or in the process of selecting rime + tone unit for preparation. Another possibility is that when only onset phoneme is shared (Experiment 1), Grade 1 children used it as the preparation unit and showed the preparation effect; however, when the initial 
atonal syllable was shared or available (Experiment 2), the atonal syllable inhibited the naming response. We still considered the inhibition as evidence for the importance and primacy of syllable in Mandarin. It may be that due to their less broad and fine-grained lexical knowledge than other literate groups, Grade 1 children may preactivate syllable neighbors that share the same initial tonal syllable and/or atonal syllable with the target. The lexical competition of syllable neighbors may have led to an overall interference effect. Unfortunately, the present study was not able to tease apart these two possibilities and future research is called for to better understand the underlying mechanism of the inhibition effect of atonal syllable in Grade 1 children.

For kindergartners, since they did not show onset phoneme preparation effect (Experiment 1) and may not have developed the ability to represent and process tone independently, it is more likely that the strong link between syllable and tone led to the inhibition. Kindergartners may represent and process tonal syllable as an integral unit, and the shared syllable with different tones led to difficulties and inhibition at the articulatory locus or at the stage of selecting tonal syllable. Future research is needed to test this hypothesis.

It is important to acknowledge that the present study recruited a limited number of participants in each of the three experiments, and some of the findings are likely to be anecdotal based on Bayes factor scores (e.g., the onset facilitation effect in Experiment 1 was at the borderline for Grade 1 children). However, it is equally important to note that, even with the limited number of participants, the Bayes factor scores suggest that the following effects were substantial: (a) the null onset preparation in kindergartens and skilled readers (Grade 4 and adults); (b) the atonal syllable interference in kindergartners; (c) the atonal syllable facilitation in skilled readers but the null effect in Grade 2; and (d) the tonal syllable facilitation in kindergartners and Grade 2. Furthermore, the onset facilitation effect reached significance in Grade 1 children, and a significant Grade Level $\times$ Context interaction was shown in Experiment 1. Taken together, the current study shed new light on the contribution of orthographic experience to phonological preparation. Clearly, future research with a larger sample size is called for to improve the power of the study and to produce more reliable, less ambiguous results.

It is also important to acknowledge that only Grade 2 children and kindergartners were recruited in the third set of experiments, where the initial tonal syllable was shared in the homogeneous lists. On the one hand, the first two experiments had already shown that onset phoneme was the preparation unit in Grade 1 children (Experiment 1) and atonal syllable was the preparation unit in Grade 4 children and adults (Experiment 2). On the other hand, it is not surprising that speakers benefit from the foreknowledge of the whole tonal syllable when producing a disyllabic word in a syllable-timed language. However, testing all the grade levels could help make a stronger claim. In addition, the orthographic experience difference among the grade levels was not clear-cut - it may be confounded with age, and all groups have diverse orthographic experience (e.g., kindergartners do have some character experience and Grade 1 children also read characters). However, it will be challenging or even impossible to find well-matched participants that only differ in orthographic experience (e.g., one group is only exposed to pinyin while the other is only exposed to characters). In the future, a training study may be a way to better control the potential confound factors.

\section{Conclusion}

The present study investigated the development of phonological preparation in spoken word production in native Mandarin speakers. Taken together, we showed that orthographic experience may influence phonological preparation likely through modifying the grain size of phonological representation, and attention may also play a role. Speakers with experience with multiple orthographies are flexible in the selection of the starting point or the first selectable unit in phonological preparation for spoken word production. Attention may be involved in phonological preparation, influencing phonological encoding and retrieval. We suggest that orthographic experience and attention jointly contribute to phonological preparation and need to be taken into account in studying spoken word production.

Acknowledgements The authors sincerely thank all the children and teachers in the primary school in Tianjin who assisted our data collection of Grade 1 to Grade 4 children and Dr. Li who assisted our data collection of kindergarten children in Nanjing. Drs. William Idsardi, Robert L. Sleve, and Yi-Ting Huang offered their helpful feedback and comments on an early version of this manuscript. Dr. Victor Ferreira provided helpful comments on the revision of this manuscript.

\section{Compliance with ethical standards}

Declaration of conflicting interests The authors declared that they had no conflicts of interest with respect to their authorship or the publication of this article.

Funding This research was supported in part by a National Science Foundation Doctoral Dissertation Improvement Grant (BCS-451722) and a NSF IGERT grant to UMD (DGE-0801465). Any opinions, findings, and conclusions or recommendations expressed in this material are those of the authors and do not necessarily reflect the views of the NSF. 


\section{Appendix A The full stimuli in all the experiments}

Table 8 All stimuli used in Experiment 1 (onset manipulated)

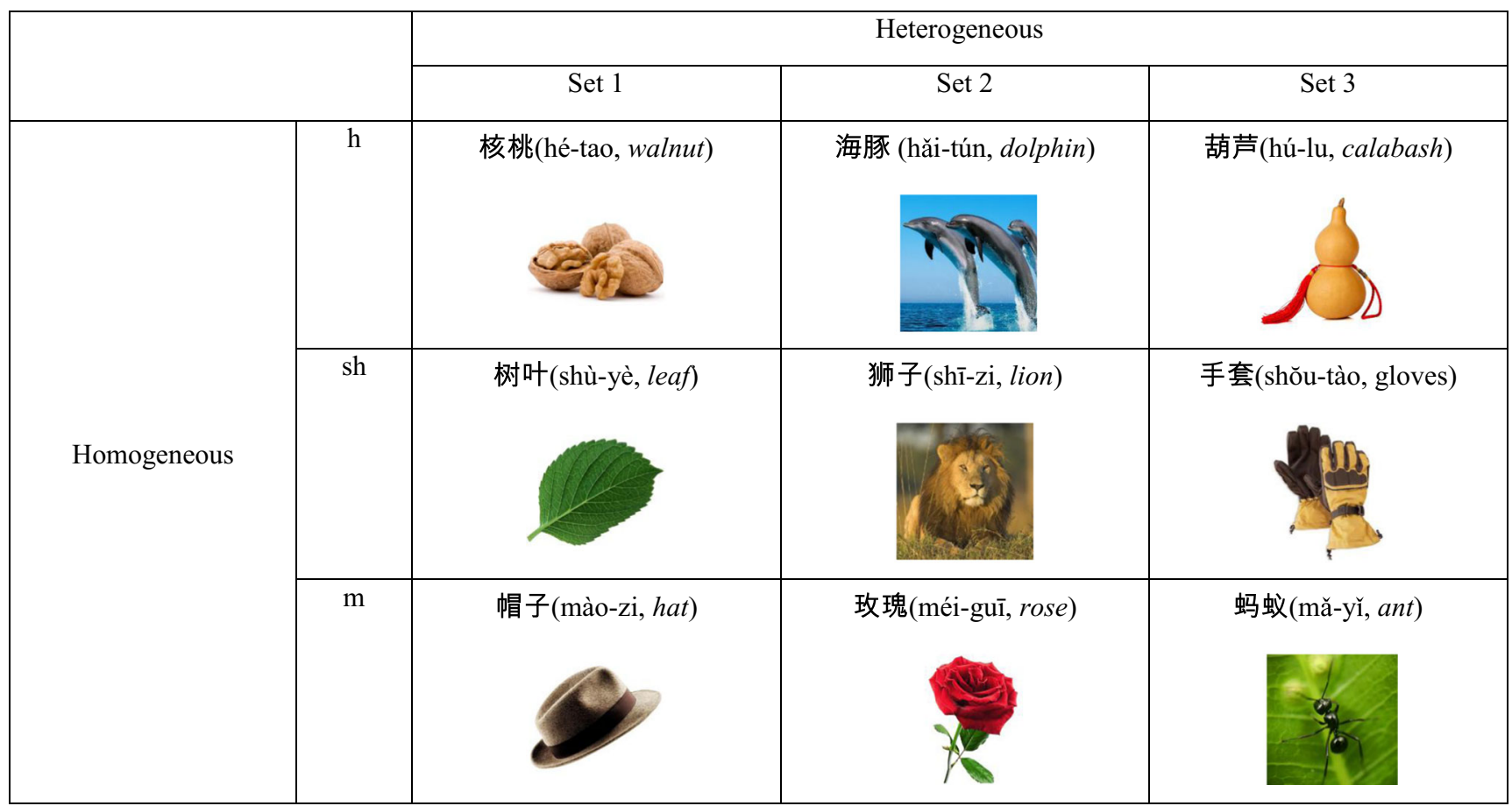

Note. The first symbol in the parentheses is the pinyin symbol of the corresponding character

Table 9 All stimuli used in Experiment 2 (initial atonal syllable manipulated)

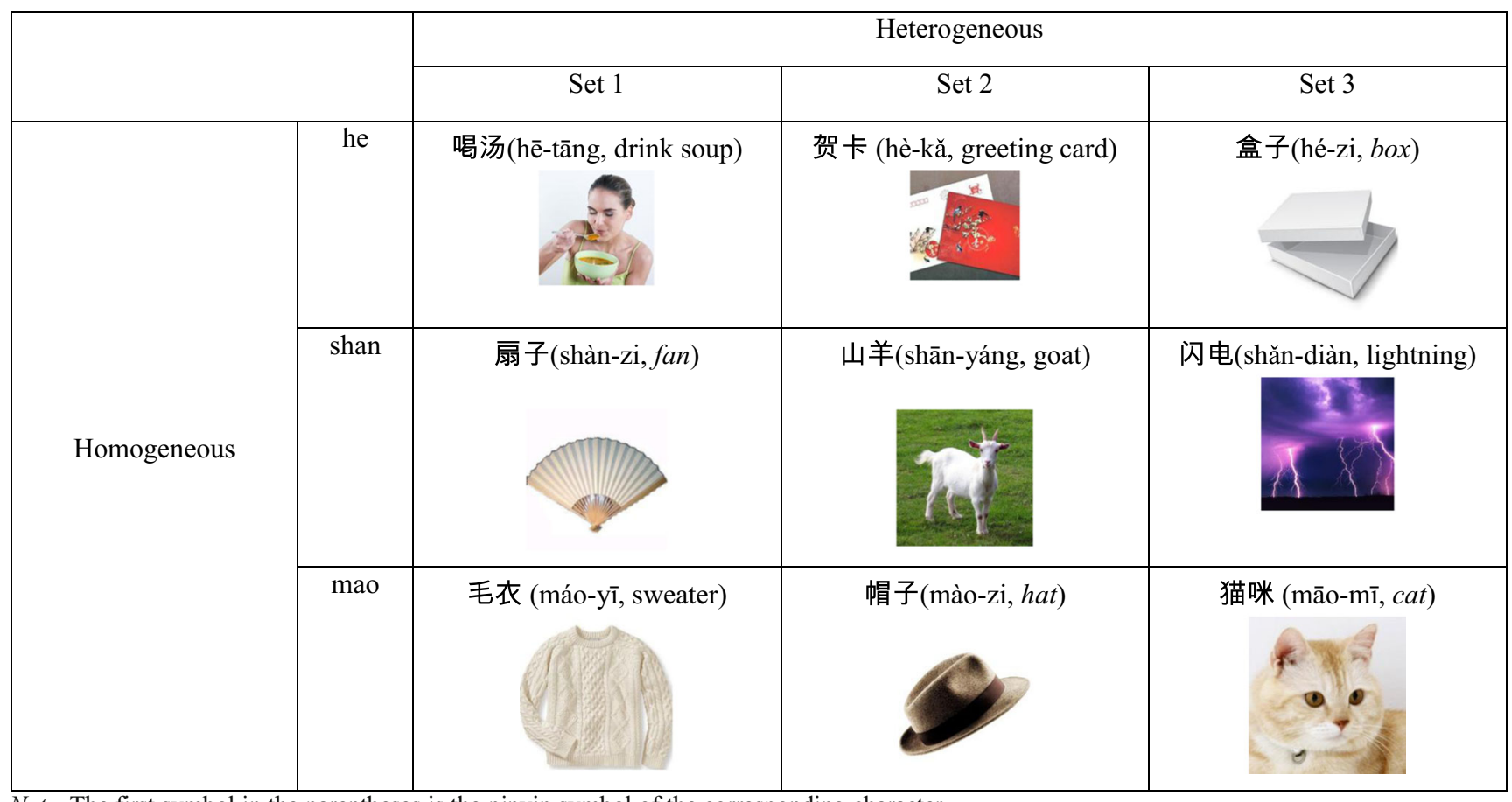

Note. The first symbol in the parentheses is the pinyin symbol of the corresponding character 
Table 10 All stimuli used in Experiment 3 (initial tonal syllable manipulated)

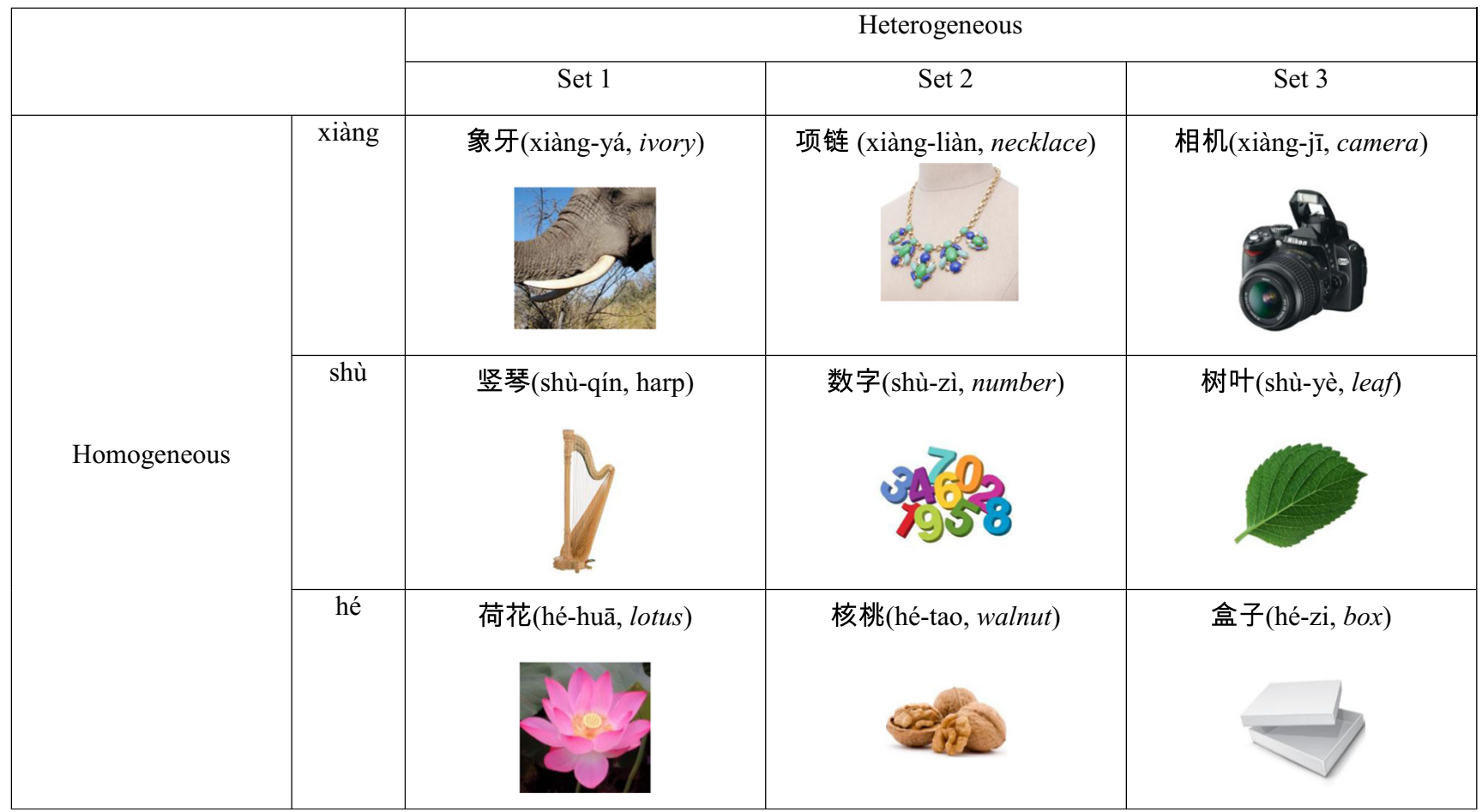

Note. The first symbol in the parentheses is the pinyin symbol of the corresponding character

\section{References}

Alario, F.-X., Perre, L., Castel, C., \& Ziegler, J. C. (2007). The role of orthography in speech production revisited. Cognition, 102(3), 464 475. doi:10.1016/j.cognition.2006.02.002

Bates, D., Maechler, M., Bolker, B., \& Walker, S. (2013). Lme4: Linear mixed-effects models using Eigen and S4 (R Package Version 1.0-5). Retrieved from http://CRAN.R-project.org/package=lme4

Castles, A., \& Coltheart, M. (2004). Is there a causal link from phonological awareness to success in learning to read? Cognition, 91(1), 77-111. doi:10.1016/S0010-0277(03)00164-1

Chen, J.-Y., Chen, T.-M., \& Dell, G. S. (2002). Word-form encoding in Mandarin Chinese as assessed by the implicit priming task. Journal of Memory and Language, 46(4), 751-781. doi:10.1006/jmla.2001.2825

Chen, J.-Y., \& Li, C.-Y. (2011). Word form encoding in Chinese word naming and word typing. Cognition, 121(1), 140-146. doi:10.1016/ j.cognition.2011.05.009

Chen, J.-Y., O'Séaghdha, P. G., \& Chen, T.-M. (2016). The primacy of abstract syllables in Chinese word production. Journal of Experimental Psychology: Learning, Memory, and Cognition, 42(5), 825-836. doi:10.1037/a0039911

Chen, T.-M., \& Chen, J.-Y. (2013). The syllable as the proximate unit in Mandarin Chinese word production: An intrinsic or accidental property of the production system? Psychonomic Bulletin \& Review, 20(1), 154-162. doi:10.3758/s13423-012-0326-7

Damian, M. F., \& Bowers, J. S. (2009). Assessing the role of orthography in speech perception and production: Evidence from picture-word interference tasks. European Journal of Cognitive Psychology, 21(4), 581-598.
Ehri, L. C., \& Ryan, E. B. (1980). Performance of bilinguals in a pictureword interference task. Journal of Psycholinguistic Research, 9(3), 285-302.

Ferreira, V. S. (2010). Language production. Wiley Interdisciplinary Reviews: Cognitive Science, 1(6), 834-844. doi:10.1002/wcs.70

Forster, K. I., \& Forster, J. C. (2003). DMDX: A windows display program with millisecond accuracy. Behavior Research Methods, Instruments, \& Computers: A Journal of the Psychonomic Society, Inc, 35(1), 116-124.

Hanley, J. R. (2005). Learning to read in Chinese. In The science of reading, a handbook (pp. 296-315). Oxford, UK: Blackwell.

Huang, H. S., \& Hanley, J. R. (1995). Phonological awareness and visual skills in learning to read Chinese and English. Cognition, 54(1), 73 98. doi:10.1016/0010-0277(94)00641-W

Hyman, L. M. (1985). A theory of phonological weight. Dordrecht: Foris. (Reprinted by CSLI, Stanford University, 2003).

Ida, K., Nakayama, M., \& Lupker, S. J. (2015). The functional phonological unit of Japanese-English bilinguals is language dependent: Evidence from masked onset and mora priming effects. Japanese Psychological Research, 57(1), 38-49. doi:10.1111/jpr.12066

Inagaki, K., Hatano, G., \& Otake, T. (2000). The effect of kana literacy acquisition on the speech segmentation unit used by Japanese young children. Journal of Experimental Child Psychology, 75(1), 70-91. doi:10.1006/jecp.1999.2523

Jacobs, C. L., \& Dell, G. S. (2014). 'hotdog', not 'hot' 'dog': the phonological planning of compound words. Language, cognition and neuroscience, 29(4), 512-523.

Kureta, Y., Fushimi, T., Sakuma, N., \& Tatsumi, I. F. (2014). Orthographic influences on the word-onset phoneme preparation effect in native Japanese speakers: Evidence from the word-form 
preparation paradigm. Japanese Psychological Research, 57(1), 50 60. doi:10.1111/jpr.12067

Kureta, Y., Fushimi, T., \& Tatsumi, I. F. (2006). The functional unit in phonological encoding: Evidence for moraic representation in native Japanese speakers. Journal of Experimental Psychology: Learning, Memory, and Cognition, 32(5), 11021119. doi:10.1037/0278-7393.32.5.1102

Kuznetsova, A., Brockhoff, P.B., \& Christensen, R. H. B. (2013). ImerTest: Tests for random and fixed effects for linear mixed effect models (lmer objects of lme4 package) (R Package Version 2.0-0). Retrieved from http://CRAN.R-project.org/package=lmerTest

Li, C., Wang, M., \& Davis, J. A. (2015). The phonological preparation unit in spoken word production in a second language. Bilingualism: Language and Cognition, FirstView, 1-16. doi:10.1017/ S1366728915000711.

Li, C., Wang, M., \& Idsardi, W. (2015). The effect of orthographic form-cuing on the phonological preparation unit in spoken word production. Memory \& Cognition, 43(4), 563578. doi:10.3758/s13421-014-0484-0

Li, H., Shu, H., McBride-Chang, C., Liu, H., \& Peng, H. (2012). Chinese children's character recognition: Visuo-orthographic, phonological processing and morphological skills. Journal of Research in Reading, 35(3), 287-307. doi:10.1111/j.1467-9817.2010.01460.x

Lukatela, K., Carello, C., Shankweiler, D., \& Liberman, I. Y. (1995). Phonological awareness in illiterates: Observations from Serbo-Croatian. Applied Psycholinguistics, 16(04), 463-488. doi:10.1017/S0142716400007487

McBride-Chang, C., Bialystok, E., Chong, K. K. Y., \& Li, Y. (2004). Levels of phonological awareness in three cultures. Journal of Experimental Child Psychology, 89(2), 93-111. doi:10.1016/j.jecp.2004.05.001

Meyer, A. S. (1990). The time course of phonological encoding in language production: The encoding of successive syllables of a word. Journal of Memory and Language, 29(5), 524-545. doi:10.1016/0749-596X(90)90050-A

Meyer, A. S. (1991). The time course of phonological encoding in language production: Phonological encoding inside a syllable. Journal of Memory and Language, 30(1), 69-89. doi:10.1016/0749-596X(91)90011-8

Morais, J., Cary, L., Alegria, J., \& Bertelson, P. (1979). Does awareness of speech as a sequence of phones arise spontaneously? Cognition, 7(4), 323-331. doi:10.1016/0010-0277(79)90020-9

O'Séaghdha, P. G. (2015). Across the great divide: Proximate units at the lexical-phonological interface. Japanese Psychological Research, 57(1), 4-21. doi:10.1111/jpr.12074

O’Seaghdha, P. G., Chen, J.-Y., \& Chen, T.-M. (2010). Proximate units in word production: Phonological encoding begins with syllables in Mandarin Chinese but with segments in English. Cognition, 115(2), 282-302. doi:10.1016/j.cognition.2010.01.001

O’Séaghdha, P. G., \& Frazer, A. K. (2014). The exception does not rule: Attention constrains form preparation in word production. Journal of Experimental Psychology: Learning, Memory, and Cognition, 40(3), 797-810. doi:10.1037/a0035576

Development Core Team, R. (2008). R: A language and environment for statistical computing. Vienna: R Foundation for Statistical Computing. Retrieved from http://www.R-project.org

Read, C., Zhang, Y., Nie, H., \& Ding, B. (1986). The ability to manipulate speech sounds depends on knowing alphabetic writing. Cognition, 24(1), 31-44. doi:10.1016/0010-0277(86)90003-X

Roelofs, A. (2006). The influence of spelling on phonological encoding in word reading, object naming, and word generation. Psychonomic Bulletin \& Review, 13(1), 33-37.

Roelofs, A. (2015). Modeling of phonological encoding in spoken word production: From Germanic languages to Mandarin Chinese and Japanese. Japanese Psychological Research, 57(1), 22-37.

Rouder, J. N., Speckman, P. L., Sun, D., Morey, R. D., \& Iverson, G. (2009). Bayesian $t$ tests for accepting and rejecting the null hypothesis. Psychonomic bulletin \& review, 16(2), 225-237

Santiago, J. (2000). Implicit priming of picture naming: A theoretical an methodological note on implicit priming task. Psicológica: Revista de Metodología Y Psicología Experimental, 21(1), 39-60.

Sevald, C. A., \& Dell, G. S. (1994). The sequential cuing effect in speech production. Cognition, 53, 91-127.

Shu, H., Peng, H., \& McBride-Chang, C. (2008). Phonological awareness in young Chinese children. Developmental Science, 11(1), 171-181. doi:10.1111/j.1467-7687.2007.00654.x

Sullivan, M. P. (1999). The nature of phonological encoding during spoken word retrieval. Language and Cognitive Processes, 14(1), 15-45.

Tseng, C. H., Huang, K. Y., \& Jeng, J. Y. (1996). The role of the syllable in perceiving spoken Chinese. Proceeding of National Science Council (ROC) Part C: Humanities and Social Sciences, 6, 71-86.

Verdonschot, R. G., Kiyama, S., Tamaoka, K., Kinoshita, S., La Heij, W., \& Schiller, N. O. (2011). The functional unit of Japanese word naming: Evidence from masked priming. Journal of Experimental Psychology: Learning, Memory, and Cognition, 37(6), 1458-1473. doi: $10.1037 / \mathrm{a} 0024491$

Verdonschot, R. G., Nakayama, M., Zhang, Q., Tamaoka, K., \& Schiller, N. O. (2013). The proximate phonological unit of Chinese-English bilinguals: Proficiency matters. PLoS ONE, 8(4), e61454. doi:10. 1371/journal.pone.0061454

Wang, M., \& Gao, W. (2011). Subsyllabic unit preference in learning to read pinyin syllables. Contemporary Educational Psychology, 36(2), 142-151. doi:10.1016/j.cedpsych.2011.02.001

You, W., Zhang, Q., \& Verdonschot, R. G. (2012). Masked syllable priming effects in word and picture naming in Chinese. PLOS ONE, 7, e46595.

Ziegler, J. C., \& Goswami, U. (2005). Reading acquisition, developmental dyslexia, and skilled reading across languages: A psycholinguistic grain size theory. Psychological Bulletin, 131(1), 3-29. doi:10. 1037/0033-2909.131.1.3 